\title{
Research of the reactor vessel sealing surface inspection parallel robot control system
}

\author{
Tao Zhang ${ }^{1, a^{*}}$, Qingsong Liu $^{2, b}$,Tenglong $\mathrm{Li}^{3, \mathrm{~b}}$,Jiajie Chen ${ }^{4, \mathrm{~b}}$ and Liangzhong \\ Jiang ${ }^{5, c}$ \\ ${ }^{1}$ China Nuclear Power Technology Research Institute, Shenzhen, China \\ ${ }^{2}$ China Nuclear Power Technology Research Institute, Shenzhen, China \\ ${ }^{3}$ China Nuclear Power Technology Research Institute, Shenzhen, China \\ ${ }^{4}$ China Nuclear Power Technology Research Institute, Shenzhen, China \\ ${ }^{5}$ China Nuclear Power Technology Research Institute, Shenzhen, China \\ azhangta0122285@cgnpc.com.cn, ${ }^{\mathrm{b}}$ liuqingsong@cgnpc.com.cn, ${ }^{\mathrm{c}}$ litenglong@cgnpc.com.cn, ${ }^{\mathrm{d}} \mathrm{chenji}$ \\ ajie@cgnpc.com.cn, jianglzh88@163.com
}

Keywords: Reactor Vessel, Parallel Robot, Movement Control, Inspection, Path Planning.

Abstract: Based on the computer control technology and confocal white light measurement, used the visual detection to plan the path, proposed a control algorithm for the detection and location, designed a control system for the parallel robot to inspect the reactor vessel sealing surface, realized the automatic positioning and detection of scratch areas on pressure vessel sealing surface, and measured width and depth of the scratch as well. Experimental verification showed that it can detect ca. $0.15 \mathrm{~mm}$ width and $0.025 \mathrm{~mm}$ deep scratches, and successfully applied in nuclear power plant.

\section{Introduction}

Nuclear plants need to open the reactor vessel for reloading fuel and maintenance at the end of the nuclear fuel cycle. Usually There are some matter (such as dust, rust), marks and scratches on the sealing surface of the pressure vessel, they will affect the sealing performance of pressure vessel $^{[1]}$.Therefore, during each refueling overhaul, the sealing surface needs to be grinded ,polished, and inspected. At present, the pressure vessel sealing surface grinding and polishing machines can not inspect the surface, the surface inspection usually needs to be done manually, and the scratch data can not be measured accurately. It not only affects the working efficiency, but also increases the radiation dose of workers.

According to the sealing surface of nuclear power plant pressure vessel technology specification and user needs, combined with the reactor vessel sealing surface automatic polishing machine, by using the method of robot visual and optical measurement, designed a kind of reactor vessel sealing surface inspection parallel robot, realized the automatic recognition and detection of scratches on the pressure vessel sealing surface.

\section{The reactor vessel sealing surface inspection parallel robot}

The reactor vessel sealing surface automatic polishing machine can clear away the dust, rust, indentation, and make the surface roughness coefficient reached 0.8 . Due to the effect of vibration, the automatic polishing machine can only preview the surface, identify and record the scoring area, can not measure the depth of the scratch. In order to measure the scratch depth, width, the sealing surface inspection parallel robot was designed. The robot (see Fig 1) has 4 degrees of freedom, they are circular movement along pressure vessel, $\mathrm{X}, \mathrm{Y}$ and $\mathrm{Z}$ linear movement. 


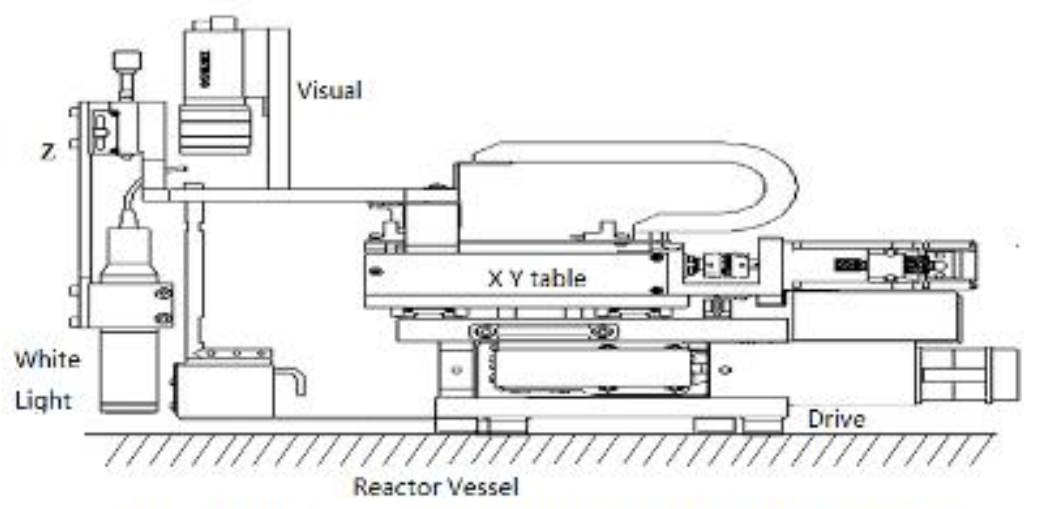

Fig. 1 The reactor vessel sealing surface inspection parallel robot

\section{Path planning and movement control}

Image coordinate transformation

The object coordinate is established through the axis of XY, the image coordinate is established through image plane level (x) and vertical (y) direction (pixel value). The transformation between the two coordinate is as follow.

$$
\left[\begin{array}{l}
\mathrm{x} \\
\mathrm{y}
\end{array}\right]=\left[\begin{array}{cc}
k_{1} & 0 \\
0 & k_{2}
\end{array}\right]\left[\begin{array}{l}
X \\
Y
\end{array}\right]+\left[\begin{array}{c}
X_{0} \\
Y_{0}
\end{array}\right]
$$

$\mathrm{k}_{1}, \mathrm{k}_{2}$ indicate the amplification factor, $\mathrm{X}_{0}, \mathrm{Y}_{0}$ indicate the offset, they are constant. When the XY table is in the original position, by measuring positions of two given points in the image coordinate, the equations is solved, thus the amplification coefficient and offset are obtained, the demarcation of the image measurement results is done.

Path planning of the scratch width measurement

In order to accurately measure the width of the scratch, it needs to identify the widest position, usually takes 4 measurement positions. The two value processing ${ }^{[2][3]}$ of image acquired by the robot vision can remove the background noise and obtain the clearly scratch outline. By specifying or automatic segmentation and windowing of the image, the scratch width measurement area was also obtained.

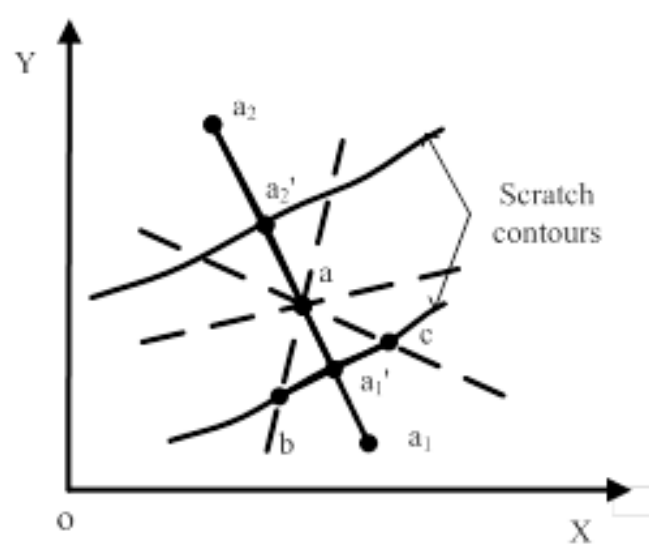

Fig.2 Schematic diagram of scratch width measurement algorithm

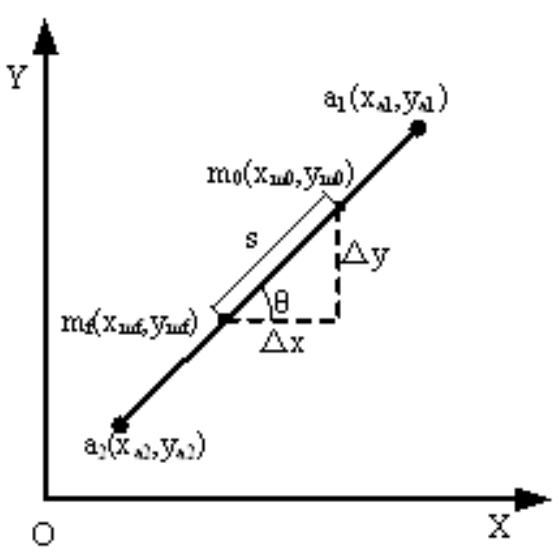

Fig. $3 \mathrm{~s}$ and $\mathrm{X}, \mathrm{Y}$ axis diagram

The grey image barycenter $\mathrm{a}\left(\mathrm{x}_{\mathrm{a}}, \mathrm{y}_{\mathrm{a}}\right)$ is the feature point of the scratch width measurement area. The line equation contained $\mathrm{a}$ is as follow.

$$
y=\operatorname{tg} \theta\left(x-x_{a}\right)+y_{a} .
$$


$\theta$ is the angle between the line which contains a and $\mathrm{X}$. Edge detection of the image along this line can find points $\mathrm{a}^{\prime}\left(\mathrm{x}_{\mathrm{a}}{ }^{\prime}, \mathrm{y}_{\mathrm{a}}{ }^{\prime}\right)$ and $\mathrm{a}^{\prime \prime}\left(\mathrm{x}_{\mathrm{a}}{ }^{\prime \prime}, \mathrm{y}_{\mathrm{a}}{ }^{\prime \prime}\right)$, the length of $\mathrm{a}^{\prime} \mathrm{a}$ "is $\mathrm{L}$.

$$
L=\sqrt{\left(x_{a}^{\prime}-x_{a}^{\prime \prime}\right)^{2}+\left(y_{a}^{\prime}-y_{a}^{\prime \prime}\right)^{2}} \text {. }
$$

In order to find the minimum $\mathrm{L}, \theta$ is any value which is multiples of $3^{\circ}$ in the range of $\left[0{ }^{\circ}\right.$, $360^{\circ}$ ] .along these lines for 120 times edge detections of the image can calculate the distance of those two endpoints, the minimum distance value is the scratch width value (see Figure 2).

The target movement path planning of optical measurement system

Using the white light confocal optical measurement system to measure the depth of scratch, it needs to control XY table to make the light point to move along the vertical line of the scratches contour tangent and pass the grey image barycenter $\mathrm{a}\left(\mathrm{x}_{\mathrm{a}}, \mathrm{y}_{\mathrm{a}}\right)$. Because the radius of curvature of the scratch contour line is approximate infinitely small, the straight line between two points at the same side on the scratch contour is approximate tangent to scratch contour (see Figure2).

The grey image barycenter is also the feature point to measure the scratch depth. The nearest two points of the line to measure the scratch width are $b\left(x_{b}, y_{b}\right)$ and $c\left(x_{c}, y_{c}\right)$, the equation of vertical line of bc which contains a is as follow.

$$
y-y_{a}=-\frac{x_{c}-x_{b}}{y_{c}-y_{b}}\left(x-x_{a}\right)=\operatorname{tg} \theta\left(x-x_{a}\right) \text {. }
$$

Optical measurement system scans the scratch along this straight line. The light spot diameter is $8 \mu$ $\mathrm{m}$, so path planning of every $8 \mu \mathrm{m}$ will not miss any one measurement point. The two light spots measurement height difference is the relative depth of the spot, the distance between the start and end points of scratch contour can also be used to measure the scratch width.

$\mathrm{a}_{1}{ }^{\prime}\left(\mathrm{x}_{\mathrm{a} 1}{ }^{\prime}, \mathrm{y}_{\mathrm{a} 1}{ }^{\prime}\right)$ and $\mathrm{a}_{2}{ }^{\prime}\left(\mathrm{x}_{\mathrm{a} 2}{ }^{\prime}, \mathrm{y}_{\mathrm{a} 2}{ }^{\prime}\right)$ are the points at the scratch contour line. $\mathrm{a}_{1}\left(\mathrm{x}_{\mathrm{a} 1}, \mathrm{y}_{\mathrm{a} 1}\right)$ and $\mathrm{a}_{2}\left(\mathrm{x}_{\mathrm{a} 2}, \mathrm{y}_{\mathrm{a} 2}\right)$ are the start and end points. If the path margin is 1 , thus

$$
\left\{\begin{array}{l}
\left|a_{1} a_{1}{ }^{\prime}\right|=\left|a_{2} a_{2}{ }^{\prime}\right|=l \\
y-y_{a}=\operatorname{tg} \theta \quad\left(x-x_{a}\right) \\
\left|a_{1} a\right|>\left|a a_{1}{ }^{\prime}\right|,\left|a_{2} a\right|>\left|a a_{2}{ }^{\prime}\right|
\end{array}\right.
$$

It can determine the coordinates of $\mathrm{a}_{1}$ and $\mathrm{a}_{2}$, and the straight line $\mathrm{a}_{1} \mathrm{a}_{2}$ is the target movement path of the optical measurement system for scratching depth measurement.

Movement control of the XY table

If $\mathrm{s}$ is the path planning interval( $\mathrm{s}=8 \mu \mathrm{m}), \triangle \mathrm{x}$ and $\triangle \mathrm{y}$ are the components along $\mathrm{X}$ and $\mathrm{Y}$ (see Figure $3)$. The time for the optical system to move $s$ distance is $t_{f}$, the position of the light spot is $m\left(x_{m}, y_{m}\right)$, and the initial and terminal position are $\mathrm{m}_{0}\left(\mathrm{x}_{\mathrm{m} 0}, \mathrm{y}_{\mathrm{m} 0}\right)$ and $\mathrm{m}_{\mathrm{f}}\left(\mathrm{x}_{\mathrm{mf}}, \mathrm{y}_{\mathrm{mf}}\right)$, the initial and terminal velocity are $\mathrm{v}_{0}\left(\mathrm{v}_{\mathrm{x} 0}, \mathrm{v}_{\mathrm{y} 0}\right)$ and $\mathrm{v}_{\mathrm{f}}\left(\mathrm{v}_{\mathrm{xf}}, \mathrm{V}_{\mathrm{yf}}\right)$.

With the $\mathrm{Y}$ axis as an example, in order to ensure the continuity of the velocity and acceleration, using three degree polynomial, the path planning of the $\mathrm{Y}$ axis optical system in s range is made.

$$
\left\{\begin{array}{l}
y_{m}(t)=k_{0}+k_{1} t+k_{2} t^{2}+k_{3} t^{3} \\
y_{m}(0)=y_{m 0} \\
y_{m}\left(t_{f}\right)=y_{m f} \\
\boldsymbol{\&}_{\mathrm{m}}(0)=v_{y 0} \\
\boldsymbol{\&}_{\mathrm{m}}\left(t_{f}\right)=v_{y f}
\end{array} .\right.
$$

The equation is solved as follow. 


$$
\left\{\begin{array}{l}
k_{0}=y_{m 0} \\
k_{1}=v_{y 0} \\
k_{2}=\frac{3 s \sin \theta}{t_{f}{ }^{2}}-\frac{2}{t_{f}} v_{y 0}-t_{f} v_{y f} \\
k_{3}=-\frac{2 s \sin \theta}{t_{f}{ }^{3}}+\frac{1}{t_{f}{ }^{2}}\left(v_{y f}+v_{y 0}\right)
\end{array} .\right.
$$

By the slope of the target path, the initial position $\mathrm{y}_{\mathrm{m} 0}$ and terminal position $\mathrm{y}_{\mathrm{mf}}$ of each section of $\mathrm{s}$ distance are calculated. Because the target path is a straight line, each path of the initial velocity and terminal velocity (except the start position and end position of the target path) is the average speed. if the average movement speed of optical system is $\mathrm{v}_{\mathrm{m}}$, then

$$
V_{y f}=\frac{\Delta \mathrm{y}}{t_{f}}=V_{m} \sin \theta \text {. }
$$

Thus, values of A, B, C, D can be calculated and the motion path of $\mathrm{y}_{\mathrm{m}}(\mathrm{t})$ during each s range is also determined. The speed command of the $Y$ axis at any location is the differential coefficient of $y_{m}(t)$. Similarly path planning of $\mathrm{X}$ axis during $\mathrm{s}$ distance is made, the planning path and speed command of $\mathrm{Y}$ axis also can be calculated.

By the off-line path planning of the X, Y axis movement, based on the position feedback, the optical system speed instructions on the scanning path were got in every control cycle with look-up table method, and sent to the XY table controller. The controller can drive the XY servo motors to make the optical system to measure the scratch depth along the target path.

\section{Structure of control system}

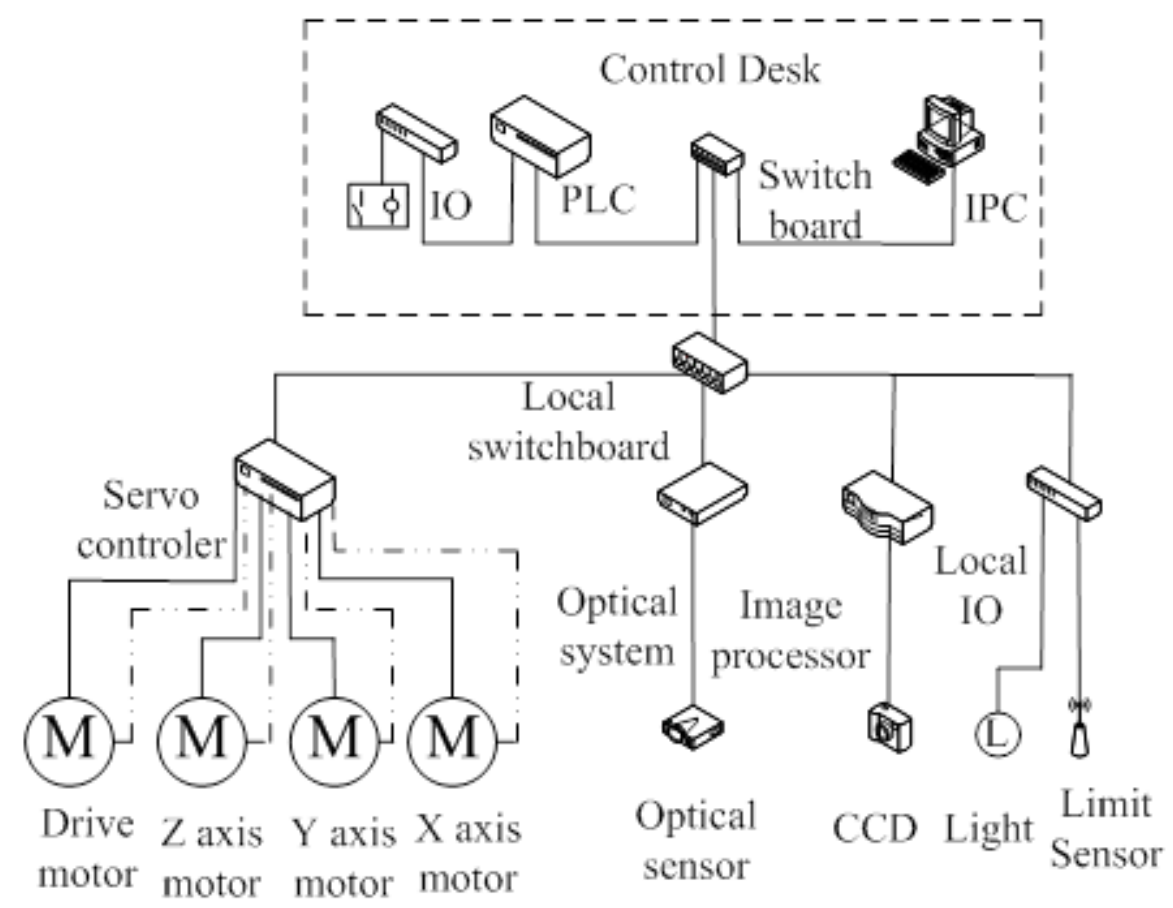

Fig. 4The structure of control system

Considering the equipment installation, power supply and the environmental requirements, the control system is arranged in the distance about $30 \mathrm{~m}$ location, away from the strong radiation area, and in order to reduce the communication and measurement problems of electromagnetic interference and signal attenuation in the transmission process, the servo drivers, robot vision and optical measurement 
system signal processing are arranged in the inspection parallel robot, the instruction of servo control system, feedback controller signal, image and optical measuring signal Communicate with remote controller by the industrial Ethernet. The computer control structure is master-slave, and is shown in figure 4.

\section{Experimental verification}

Using a surface detection component simulated pressure vessel sealing surface with scratch.The optical system light spot is $8 \mu \mathrm{m}$, and the optical system average scanning speed is set to $0.05 \mathrm{~mm} / \mathrm{s}$ to measure the scratch. Figure 5 is the scratch depth measurement curve, and from the curve the scratch depth is about $25 \mu \mathrm{m}$ and the scratch width is about $0.15 \mathrm{~mm}$.

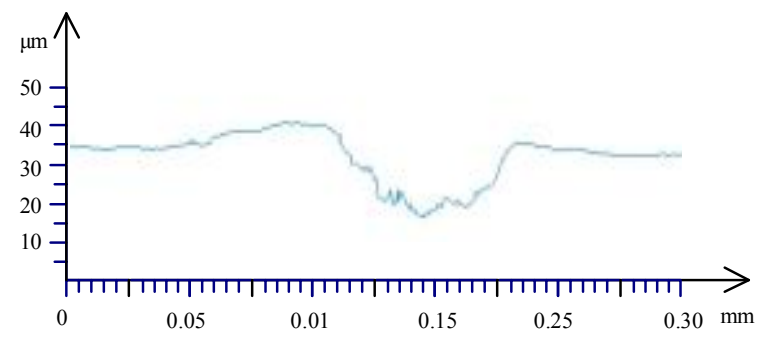

Fig. 5 The scratch depth measurement curve

\section{Conclusion}

By the methods of visual and white light confocal optical measurement, designed a kind of parallel robot used for the reactor vessel sealing surface inspection, realized the automatic recognition and measurement of scratches. Experiment showed that it can measure about $0.15 \mathrm{~mm}$ width and $0.025 \mathrm{~mm}$ deep scratches, and successfully applied to reactor vessel sealing surface inspection in nuclear power plant and provided the accurate information for the maintenance of the reactor vessel sealing surface.

\section{Reference}

[1] Zheng Lian-gang, Zhang Li-ping, YangYu and Zang Feng-gang, Seal analysis technology for reactor pressure vessel, Nuclear Power Engineering. Commun. 30( 2009)4-6.

[2] ZhangWei and Zhang Jun-jie, Surface defect detection system for steel plate based on machine vision. ShanXi Metallurgy . Commun. 132(2011)51-53.

[3] Lin Xiao-ming, Gui Ting and Hu Tong-sen, Edge detection algorithm of gray scale image based on the center of gravity .Computer Systems \& Applications. Commun. 19(2010)235-237. 